\title{
Correction to: Mesenchymal stem cells-derived exosomes modulate vascular endothelial injury via miR-144-5p/PTEN in intracranial aneurysm
}

\author{
Guojun Yang ${ }^{1} \cdot$ Hao Qin ${ }^{2} \cdot$ Bing Liu $^{1} \cdot$ Xinhong Zhao ${ }^{3} \cdot$ Hang Yin $^{2} \mathbb{D}$
}

Published online: 1 September 2021

(C) Japan Human Cell Society 2021

\section{Correction to: Human Cell (2021) 34:1346-1359 https://doi.org/10.1007/s13577-021-00571-7}

In the original publication of the article, the "Acknowledgements' and Funding" should be revised as below.

Acknowledgements We thank for the financial support from Chengde Science and Technology Research and Development Program (202006A075) and Shandong Medical and health Science and Technology Development Project for supporting our research.
Funding The study was supported by the Shandong Medical and health Science and Technology Development Project (2018WS019) and Chengde Science and Technology Research and Development Program (202006A075).

Publisher's Note Springer Nature remains neutral with regard to jurisdictional claims in published maps and institutional affiliations.

The original article can be found online at https://doi.org/10.1007/ s13577-021-00571-7.

Hang Yin

HangYinZaozhuang@163.com

1 Department of Neurosurgery, Affiliated Hospital of Chengde Medical University, Chengde City 067000, Hebei Province, People's Republic of China

2 Department of Neurosurgery, Zaozhuang Municipal Hospital, No. 41 Longtou Middle Road, Shizhong District, Zaozhuang City, Shandong Province 277100, People's Republic of China

3 Pharmacy Department, Affiliated Hospital of Chengde Medical University, Chengde City, Hebei Province 067000, People's Republic of China 